\title{
Is the 21th-Century School Library a Fiction or a Tangible Reality?
}

\author{
Marianna Edit Pataki \\ patakima@gmail.com \\ Spanish-Hungarian Bilingual High School
}

Keywords: best practice, media literacy, book-trailers, flexible library design, UX

\section{Abstract}

Digital era challenges the school library which loses connection with generation $Z$ who speaks a different digital language to all other generations. The underfinanced school libraries with little or no budget for new acquisitions are no longer information centres, the least "information authorities" for youngsters. We need the secret elixir to convert the museum-like school libraries into creative learning spaces. In times of budget cut our creativity enables us to welcome various forms of the digital language Generation $Z$ is native speaker of. By implementing simple social media like activities into our library programs we might fill the old collections with new vibe.

\section{Introduction}

The 21 st century challenges the school libraries extensively. We are losing connection with generation $\mathrm{Z}$, which speaks a different digital language compared to all other generations. The underfinanced school libraries with little or no budget for acquisition are no longer information centers, far less are authorities for them. We need the secret elixir to convert the museum-like school libraries which offer 10 to 50 years old books to teenagers, into creative learning spaces. Since we have limited or practically no budget for acquisition, we need our creativity to welcome various forms of the digital language that generation $\mathrm{Z}$ speaks fluently. Creative school librarians might be inspired by a collection of best practices at information literacy training classes.

\section{Possibilities of the Hungarian School Libraries}

Library instruction, together with improving information literacy and reading promotion are parts of the core curriculum in Hungary. School librarians have the privilege to welcome 1-10 graders to a library instruction unit each school year. These programs help students to become acquainted with the library spaces, getting to know the collection, and finding relevant information to create new content. Unfortunately, the outdated collections of school libraries overshadow these promising possibilities to motivate students to use the library. 


\section{The Library Visitors}

As practicing librarians, we do not need any scientific proof of the change of information consumption of our visitors. One can face the banality way too often: With smartphones in pockets, the students think that they can practically find any information for their studies. Unfortunately, or not, but they are right. Up to a certain level, they can find what they think is needed if they speak English well enough.

The usual librarian answer is a similar banality: To find a quality, open-access information is far more complicated and at least as time "consuming" as to search for information in the library. After the disappointing truth comes the almost necessary attack on Wikipedia from our side, and right here we have probably lost our teenage visitors for some time if not forever.

I fall into this trap way too often. I have only changed my attitude towards Wikipedia just recently, after watching a Crash Course on Navigating Digital Information with John Green, who is a great authority for my teen visitors. Green explains the positive sides of Wikipedia, like; it has more articles than in any reference book of the world, and its fast editing process compared to printed resources. He also highlights its weakness; overburdened admins cannot really apply its strict editorial policy; therefore, false information is not removed immediately from the articles; it takes some time to correct the content. He suggests that users should use Wikipedia as a starting point for getting an overview of the topics they are not familiar with, but he advises getting to the sources as quickly as possible, and conduct a study on the cited information instead of relying on the content of the free encyclopedia. (Green, 2019)

I believe the students will remember Green's advice much more than they would have remembered if I told them the same ideas. For students, it is more comfortable and fancier to accept something from a celebrity than from a teacher-librarian or a teacher. Because together with the libraries, schools and teachers had lost their authority as well. Even though we represent the same idea, students are more likely to remember, if they heard it from a celebrity than from anybody from the traditional institutes of the knowledge industry.

We have to accept that our authority is not granted, we have to earn it, or borrow it from somebody popular among teens.

The value of knowledge decreases, while creativity is appreciated. We can win the students if we combine the traditional info seeking methods with creative solutions. These solutions do not necessarily involve the most advanced IT technology and devices. They can be low-tech activities that copy the means of social media: self-presentation, reaction, feedback and give the sensation of being part of the global community, since digital culture can create a sense of togetherness.

Several pieces of research emphasize the difference between the media consumption of Generation $Y$ and Generation Z. Our students from Gen Z never lived without the internet. To be deprived of their smartphone is a significant threat in their lives. There are various ways to let them use their favorite devices and social media platforms, and this way, we can provide them with a 21 st-century like experience despite outdated school library collections. We cannot offer fresh collection, but we can embrace their well-trained skills in using social media, and their permanent need to manifest themselves in various ways. 
Here I present a small collection of school library activities, which helped to engage students to visit the school library more frequently.

\section{Best Practice}

\section{You are in the Library: The importance of self-expression}

The urbandictionary.com defines selfies as the beginning of the end of the intelligent civilization. Although the word selfie first appeared in written form only in 2002, by 2013, it was selected to be the word of the year by Oxford English Dictionary. Today selfies are unquestionable milestones in the digital narrative of one's life.

In Rutgers University, New Jersey, Professor Mary Chayko, had conducted a five weeks long seminar; "Selfies and Digital Culture," which explored the cultural significance of selfies then and now. The participant students run a blog where they posted reflections on that project.

They think that: "Selfies are the storytelling of everyday life," they create community, and empower to showcase one's life" One student addresses the "older generation" by saying: "No matter how shallow or vain older generations think we are, selfies are way for people to express themselves"

Some commenters go further and say: "Selfies are art and are meant to portray a certain aspect of reality," or modified reality to show the best-selves of the individual, and they surely are reflections of our culture and a manifestation of our individuality.

We can agree that: "Selfies help to re-live the moment and cherish the memory" and taking selfies can add to the experience one is in."

Encouraging students to take selfies in the library immediately adds a positive emotional impact on their library visit. They discover scary or funny corners, and start focusing on the books and shelves in the background. They find exciting literature by chance, and they might even loan and read them. Sharing their selfies on social media promotes the library in their social circle and might encourage somebody to visit the library. Selfies help to become acquainted with the library spaces, especially if a group tries to find the place where the selfies were taken.

One would think that to teenagers it is the easiest thing to take and post a selfie; actually, it was a surprise that some students did not feel comfortable doing it, therefore taking selfie should be optional. Students were ready to take group selfies more than single ones. The positive outcome of this program was that students conquered the library; they started to feel at home in it and came joyfully to the second class. It did not seem to foster their ability to use the library professionally, but certainly had a positive impact on students, because "Selfie taking can make almost any moment enjoyable" says one of the Rutgers Selfie Project attendants. (Intrabartola, 2016)

\section{Conclusion}

Taking selfies became part of our culture; teenagers are more familiar with it than to visit the library. If the students are asked to do something they like in an environment, they will get acquainted with it quickly, and they feel at home in it. If they are willing to share it with their network, it might promote the school library.

International Association of School Librarianship

https://iasl-online.org 


\section{Your Voice in the Library}

Several studies were conducted on why people like to "like" on Facebook. One interesting study by L. E. Sherman and others "Social Media 'Likes' Impact Teens' Brains and Behavior" states that: "The same brain circuits that are activated by eating chocolate and winning money are activated when teenagers see large numbers of "likes" on their photos or the photos of peers in a social network..." they stated it after scanning teens' brains while they used social media. They observed that: "When the teenagers saw their photos with a large number of likes, the researchers also observed activation in regions that are known as the social brain and regions linked to visual attention." They suppose that the effect gets magnified when teens are looking at likes from people who are important for them. (APS, 2019)

If the social media presence is manifested in likes and dislikes and comments, stimulates the social brain and fosters the feeling of togetherness, why not ask students to browse the selves and select random books to like or dislike?

The students got bookmarks with a like sign and were asked to explain, why would they recommend the selected books to other readers.

One can recognize interesting patterns of why some books were selected. The student's choice might mirror the current state of mind of the society. Even the effects of current political propaganda appeared on one occasion.

\section{Conclusion}

A kind of interaction started by this simple activity with the old books which help students to get to know the collection. It also helps them to feel like their voice is heard and respected, and the school library is their library.

\section{Your Book in the Library}

Reading promotion is a hard mission when the books teenagers read are not available at our school libraries. We can overcome this difficulty by encouraging students to present their favorite book's book-trailer. The complexity of transforming a reading experience into a video or a visual presentation strengthens cognitive skills effectively. Book-trailers are creative projects and are in line with the media consumption tendency of Gen $\mathrm{Z}$ who's focus turn from written resources to video content.

Book-trailers have a strong tradition in the Anglo-Saxon culture, in Hungary, they are not so common, although some publishing houses use them to promote books.

"Book-trailers are defined as a form of promotion that has to do with a reader, the twenty-first-century reader, who feels at ease in social networks and obtains information through multimedia formats including hypertextual words, images, and sound." (Taberneo Sala - Valios 2016) The authors of the study "Book-Trailers as Tools to Promote Reading in the Framework of the Web 2.0" also think that book-trailers promote not only reading but also foster digital literacy. The creative process of creating a book trailer has multiple benefits for students not only because it triggers the highest cognitive functions, but it supports media literacy as well and critical thinking within cooperative teamwork. At last but not least, it is also great fun, especially if students are asked to reimagine their favorite stories in a library setting. 
Book-trailers include compulsory elements that make the book identifiable for readers. These are the title, authors, main characters, hierarchy of characters, a setting in coherence with the story, and the storyline without spoiler. (Tabernero, 2016)

At the beginning of the project, 9th graders were asked to describe the "good book." Without exception, they explained their ideal story has a twisted but clear storyline, unpredictable end, and of course, set in a different universe.

Such stories are hard to find in the collection of the school library, but students, fortunately, own them; therefore, it is an opportunity to ask students to bring in these books virtually, in the form of a book trailer. This way, we can create a virtual mini collection beyond the outdated collection of the school library.

As a result, the library became Jurassic Park, the field of Hunger Games, and above all, Hogwarts. If the students choose books which were adapted into films, the question arose whether they have actually read the books. Although this is an open question, it is better not to determine the manual for the book-trailer, because the students might get demotivated.

\section{Conclusion}

The students enjoyed creating book-trailers because they could introduce their world and have the possibility to reimagine the story in the library. They got familiar with the library in a creative way. Some of them even came to the library to film other projects.

\section{Your School Library}

In 2016, the Portuguese School Librarians' Association celebrated its 20th anniversary. On this occasion, a short video competition was held to support school libraries. Isabel Mendinhos gave an inspirational presentation at the IFLA WLIC 2017 conference in Wroclaw. The lecture showed that teens are capable of expressing themselves more visually, than any previous generation, and enjoy making videos that support school libraries. The creative process fostered critical thinking and media literacy. When these videos were shared on social media they effectively promoted the school libraries. (Mendinhos, 2017)

It is essential for today's students to speak the language of visual storytelling since they are exposed to the influence of well-designed advertisements daily. If they understand the mechanism of promotion videos, they will be able to make sober decisions as consumers. Moreover, they will be able to present their creative potential in the job market more effectively. Not to mention the positive impact on the students' social competences since creating a video requires intensive teamwork and planning.

When students started the second unit of their use of library training in the 10th grade, they had enough knowledge of library instruction for being asked to create a short promotional video about school libraries.

After being instructed about the basic rules of storytelling like; show, don't tell; show people; be personal be true; don't be obvious; show conflict; show hidden things. They arranged their teams of collaboration and started to brainstorm intensively about the storyline of their promotional video. Every afternoon, various groups of students came to the library to film their short videos and had enjoyed the creative process.

International Association of School Librarianship

https://iasl-online.org 
Some of them even came to the library. The videos communicate key messages about school libraries, like; libraries are places where students can express themselves; find peace; make new friends; they can develop their personality by reading literature; and able to find quality information. All in all, libraries play an essential role in student development. However, they also expressed concern about the future of the library in the 21 st century, when information is available online and anywhere.

The teenagers were surprisingly shy to share their videos in a bigger circle than their class. Unfortunately, due to the school's privacy policy, these videos cannot be posted on the school's website, therefore their marketing effect is zero, but those students who created them made friends with the library and hopefully will always come in when they need quality information, when they long for peace, and also when they want to meet peers.

\section{Conclusion}

Students trust the school library, and they think it is a good place, but they consider it more as a community place than the primary information provider.

These simple examples show that budget cuts must not discourage librarians! On the contrary, we have to find creative ways to provide students with a 21 st century-like library experience at a 20th-century school library setting. We cannot change the environment, but we can update the school library programs by welcoming the digital language of Generation $\mathrm{Z}$ students into our practice. If we learn and apply their language, we might win them over in the end.

\section{How Could School Libraries Become More User-Friendly?}

"Libraries must be the cause of joy and engagement - the place you go to for new perspectives." (Bosch, 2018)

At the end of the 2nd decade of the 21 st century, there are several parallel universes.

There is the traditional school system which everywhere in the world focuses primarily on excellent results and student performance. Teachers try to use the newest methods in their classroom, but they need to focus on the results of the students since the parents and the principals focus on that too.

The only participant who is not that focused on the good results who want to feel good rather than being forced to perform well is the student. Being attached to his device and social media platforms he can't wait to have his free time when he finally can do what he wants, instead of being at school, where he has to do things others want him to do. School is on many occasions, the tedious necessity of life while in his free time, he can learn by watching youtube tutorials and play games or use apps and other services.

There is the strong heritage of the past school library system with Dewey's cataloging system and the labyrinth of shelves where the only person who comfortably finds the required resources is the librarian. Its priority is to adapt to international standards, need of the teachers and at last to the students.

The question is how school libraries which straggle behind advanced information providers can compete with those well designed online platforms, apps, and services? How can we engage students to spend their

International Association of School Librarianship

https://iasl-online.org 
free time at the library? If not with our services and collections, maybe with transforming the library space into a more stimulating learning and leisure time environment.

In the spring of 2019, it was a privilege to welcome Alicia Rey, the director of INFO-DOC in Huesca Spain, at the conference of the Hungarian School Librarians Association. She presented best practices on school libraries' transformation. Besides other inspiring examples, she mentioned Rosan Bosch's work on transforming schools and school libraries. (Bosch, 2018)

Rosan Bosch, a Dutch-born designer, internationally acknowledged public speaker who challenges established cultures and norms with design as a tool of innovation and change" In close dialogue with the users, she transforms physical spaces into meaningful experiences. Her studio worked on creating a motivating and flexible learning environment. They worked together with teachers and students to develop an optimal design. (Bosch, 2013)

As a result, they choose motivation as the headline for designing the new school. To achieve this objective, they thought holistically, where pedagogy and learning methods were combined with the design. They recognized the need for some tools which can translate the pedagogical input, the different learning methods into the language of design, and they created six principles which characterize the main ways of communication within the school environment:

1. Mountain top for frontal work and one-way communication

2. Cave education for individual learning. Where concentration on the subject and not communicating with anybody around, enclosing oneself inside is the main focus. Children wish to have places where they can hide but still can have the opportunity to reconnect with others quickly. This hiding place is a perfect opportunity to concentrate.

3. Campfire situations like; group work, the possibility to discuss, have a meeting, where students can speak loudly without disturbing others.

4. The watering hole, where people meet accidentally by the way. High level of disturbance together with fast knowledge exchange possibility.

5. Hands-on places where different materials can be touched and fine-motor skills are stimulated.

6. Higher up spaces: to fasten the heartbeat by physical activity and have the possibility to be loud.

Considering these six principles resulted in developing the school without walls, which is not the perfect description. It is better to call it a flexible environment. It does not mean furniture in wheels; it means to focus on the various ways of human activity - a school without classrooms but with a lot of differentiated learning space.

\section{Conclusion}

The flexible learning environment within libraries could help students to skill themselves to learn. Consequently, they could remain passionate and motivated during their learning process. The flexible school design communicates to students that they are individuals with different needs, and these needs are

International Association of School Librarianship

https://iasl-online.org 
respected and can be fulfilled in various ways. If they learned how they could function the best way, they would be able to adapt to change and form the new environment to their likeness and develop themselves to fit new expectations. Here we are one step further from the traditional LLL concept, which approaches learning from the aspects of skills. By putting motivation to the center of education, we might be able to prepare students to be able to learn skills that are not yet invented.

\section{Could libraries become the school without a wall within the schools with walls?}

Michael Bierut in TED talks presented the process when New York City's Municipality recognized that the majority of their schools are very old-fashioned. When thinking about their capacity, they thought to refurbish and redesign only one facility in each school, because they could not effort redecorating every school. When they thought about the possible most outcome of their refurbishing project, they choose school libraries, the hearts of schools to be renewed. They asked Michael Bierut a designer to create a logo for the redecorated libraries, a simple, but powerful design, which represents the significance of libraries. He made a meaningful design. With a simple change he expressed the importance of school libraries: LIBRARY! (Bierut, 2019)

\section{Conclusions}

From these two examples, we can see how significant role DESIGN has in our era, and simple changes like LIBRARY to LIBRARY can attract the students, and bring the school library closer to its young visitors.

\section{How to provide the best user experience in libraries?}

The user personas', the individuals' experience is the focal point when designing the library environment and the services.

In Hungarian schools, the libraries are defined by rows of shelves, which creates an optimal environment where we focus on the numerically arranged collection. It is suitable for the librarians to find the required resources quickly but does not create an inviting environment for visitors. Customers' needs had changed. They seldom come to search and loan materials, but they come to create something, or relax, to have some me time, or work in groups and of course, they come to read and study on their own and in teams as well. (Pataki, 2017)

Rosan Bosch approaches schools from the user experience perspective. What interface or what school environment makes the possible best user experience if the main focus is on motivating students instead of focusing on their scientific results. For some reason, she seems to suppose that motivated students will perform well in life, in the unforeseeable future, they will stay able to redesign themselves in the future world. Let's accept this perspective and create a motivating school library environment, where different activities can run simultaneously, which results in the possible best user experience.

Maybe we can start to reimagine the school library just by drawing a floorplan of the school library and find the focal points where one-way communication, individual learning, teamwork, and hands-on experience, and spontaneous meetings and knowledge transfer can be performed almost simultaneously.

Experts, who apply user experience to library services and places, and examine how users interact with libraries' physical spaces suggest focusing on five touchpoints. The website informs the users of the library before visiting it; therefore, it is essential to have a well-constructed, informative, and appealing

International Association of School Librarianship

https://iasl-online.org 
website. After entering the library, the service desk is the first touchpoint for the visitors; therefore, it is crucial to rethink what does it communicate. Whether it is the barricade of the librarian or a more open area. Signage and other wayfinding systems also play a crucial part in providing the best possible user experience. At last but not at least the layout and the equipment of the whole library can add a lot to a positive user experience. (Pshock, 2017)

\section{Conclusions}

No one can predict the future of the school libraries. If school librarians stay open-minded and desire to provide the best user experience in the school library - maybe without walls - and focus on the need of students, who want to be "themselves" in the library, want their voice being heard, and want to express themselves by being engaged in different creative projects. The students will be our best allies to find the way and keep the school libraries on existing throughout the 21 st century. Let us build school L!BRARIES! for the students, together with students!

\section{REFERENCES}

APS Association on Psychological Science. (2016). Social Media' Likes' Impact Teens' Brains and Behavior;APS:https://www.psychologicalscience.org/news/releases/social-media-likes-impact-tee ns-brains-and-behavior.html (accessed August 04, 2019).

Bierut, Michael. (2017). How to design a library that makes kids want to read?; TEDx Talks, Retrieved from YouTube: https://www.youtube.com/watch?v=YsA_JTeHJ6A, (accessed August 06, 2019).

Bosch, Rosan. (2018). New library functions for co-creation and community; Rosanboschstudio.com: https://rosanbosch.com/en/approach/new-library-functions-co-creation-and-community (accessed August 01, 2019).

Bosch, Rosan. (2018).Desenar escuelas de donde los ninos no quieren irse; Zaragoza, TEDx Talks, Retrived from YouTube: https://www.youtube.com/watch? $v=$ mfCa5N42tBE, (accessed August 03, 2019).

Bosch, Rosan. (2013). Designing for a better world starts at school: Rosan Bosch at TEDxIndianapolis; TEDx Talks, Retrieved from YouTube: https://www.youtube.com/watch?v=q5mpeEa_VZo, (accessed August 03, 2019).

Green, John. (2019). Whom Can You Trust? Crash Course Navigating Digital Information \#4ash; Crash Course, Retrieved from YouTube: https:/www.youtube.com/watch?v=o93pM-b97HI, (accessed August 03, 2019).

Intrabartola, Lisa. (2016). The Significance of Selfies - Then and Now: Rutgers' Byrne seminar encourages students to look closely at their lives in a digital age; Rutgers Today: Teaching, URL: https://rutgersselfieproject.wordpress.com/ (accessed August 03, 2019).

Mendinhos, Isabel. (2017). Advocacy through videos: Short movies on school libraries; Paper presented at: IFLA WLIC 2017 - Wrocław, Poland - Libraries. Solidarity. Society. In Session 242 Audiovisual and Multimedia, Information Literacy and School Libraries.

International Association of School Librarianship

https://iasl-online.org 
Pataki, Marianna Edit. (2017). Readers, Libraries, and Librarians of the Digimodern Era = Olvasók, könyvtárak és könyvtárosok a digimodern korban; Digitális írástudás mühely, Budapest, FSZEK, 2017.URL:http://www.azenkonyvtaram.hu/documents/11543/34323/Pataki+Mariann.pdf/41802d 44-b766-4ec6-8aaa-b19c398ac7c2 (accessed August 01, 2019).

Pshock, D. (2017). The User Experience of Libraries: Serving The Common Good; User Experience Magazine, 17(2), Retrieved from https://uxpamagazine.org/the-user-experience-of-libraries/ (accessed August 06, 2019).

Tabernero, Sala, Rosa \& VALIOS, Virginia. (2016). Book-Trailers as Tools to Promote Reading in the Framework of the Web 2.0. New Review of Children's Literature and Librarianship. 22. 53-69. 10.1080/13614541.2016.1120071. 